\title{
The effect of the Information-Motivation-Behavioral skills (IMB) model variables on Orthorexia Nervosa behaviors of pregnant women
}

Ayşe Taştekin Ouyaba ( $\sim$ ayse.tastekin@hotmail.com )

Afyonkarahisar Health Sciences University https://orcid.org/0000-0002-5907-1140

Pınar Çiçekoğlu Öztürk

Muğla Sıtkı Koçman University

\section{Research Article}

Keywords: Information-Motivation-Behavioral Skills Model, pregnancy, Orthorexia Nervosa

Posted Date: March 30th, 2021

DOl: https://doi.org/10.21203/rs.3.rs-332222/v1

License: @ (i) This work is licensed under a Creative Commons Attribution 4.0 International License. Read Full License 


\section{Abstract}

Purpose This study aims to test the effect of the components of the Information-Motivation-Behavioral Skills Model on Orthorexia Nervosa (ON) behavior of pregnant women and health outcomes using a hypothetical model.

Methods The study is cross-sectional research and was carried out with 350 pregnant women who had the Non-Stress Test in the obstetrics outpatient clinic of a university hospital. The participants were selected using the convenience sampling method. The data were collected with a questionnaire. Data were analyzed using the structural equation model.

Results It was found that $26.6 \%$ of pregnant women had an ON tendency. Higher levels of information on healthy eating cause more ON behaviors $(\beta=-0.25, p<.001)$. The higher motivation for healthy eating $(\beta=0.71$, $p<.001)$ and a higher tendency to ON behaviors $(\beta=-0.18, p=.001)$ are associated with better health outcomes.

Conclusion Our findings show that high levels of information and motivation about healthy eating affect ON tendency and health outcomes. The findings are significant in that they lead and guide the interventions for the detection, prevention, and treatment of ON during pregnancy.

Level of Evidence: Level V, cross-sectional study

\section{Introduction}

Orthorexia Nervosa (ON) has been briefly defined as an "obsession with healthy eating" [1]. The obsessions of orthorexic individuals can be related to a wide variety of issues such as pesticides in foods, foods with hormones, chemical sweeteners, preservative chemicals, food dyes, carcinogenic substances in food packaging, and product labels. $\mathrm{ON}$ is related to the content of the food consumed rather than the amount of food [2]. ON is the pathological obsession with avoiding foods perceived as "unhealthy" or "unclean." In addition to how meals are prepared, extra time is spent researching, cataloging, weighing, and measuring food, and planning and intervening in future meals [3]. However, $\mathrm{ON}$ is not yet an official diagnosis in the Diagnostic and Statistical Manual of Mental Disorders (DSM)-5 [4], it is controversial whether it is different from anorexia nervosa (AN) or bulimia nervosa [5]. On the other hand, ON can be severe and life-threatening. The phobia of eating unhealthy foods limits the consumption of certain products. Also, individuals with $\mathrm{ON}$ avoid environments where there is no suitable food for them. Therefore $\mathrm{ON}$ can lead to too much weight loss and nutritional deficiencies. In this context, ON can mean an "unhealthy addiction to healthy eating" [6].

The prevalence of ON symptoms is less than $1 \%$ in the US sample [7], 4.5\% in university students [8], $21.4 \%$ of pregnant women [9], and 35-57.8\% in high-risk groups (for example, artists, athletes, healthcare professionals, and performance artists) [10]. Women are significantly more concerned with having a slim body image and dieting than men, and as a result, are more prone to an eating disorder risk. The prevalence of eating disorders is highest among women before their reproductive years or during reproductive years, which leads to some questions about pregnancy [11]. It has been noted that eating disorders have increased in pregnant women in recent years [12]. 
Pregnancy is a process involving changes that can be a turning point for the onset and recurrence of healthy eating obsession [13]. The reasons for the obsession during pregnancy can be explained by several theories. The first is that the thought of harming the baby increases with responsibility in the pregnant woman. The second is to be overprotective against threats. The third is intrusive thoughts about the baby's safety. These thoughts cause significant anxiety in the mother and obsessive-compulsive symptoms occur [14]. Despite being acted to achieve optimum health, $\mathrm{ON}$ can lead to nutritional deficiencies, medical complications, and poor quality of life [3]. It is believed that insufficient intake of nutrients, together with the physiological changes that occur during pregnancy, causes metabolic changes in the mother and epigenetic modifications in the fetus. Therefore, it is necessary to have sufficient energy and nutrient intake during pregnancy to maintain maternal and fetal health [15].

Studies on ON generally focus on measuring its prevalence in at-risk groups [16]. Studies on ON during pregnancy are fairly limited. To the best of our knowledge, there is only one study investigating ON risk in pregnant women. The descriptive study conducted with 70 women in Turkey investigated pregnant women's obsession with healthy eating and eating attitudes [9]. The reasons for the lack of sufficient evidence regarding $\mathrm{ON}$ during pregnancy are the desire of the pregnant women to conceal this problem, the masking of ON symptoms by some nutritional problems such as anorexia, hyperemesis gravidarum, and pica, seen especially in the first trimester, and not evaluating nutritional disorders routinely during prenatal controls. $\mathrm{ON}$ is a problem that should be addressed; however, it is often overlooked during pregnancy [17]. Eating disorders and malnutrition during pregnancy increase maternal and fetal morbidity and mortality [6]. Under these conditions, the diagnosis and treatment of eating disorders during pregnancy become particularly important [18].

\section{Theoretical Framework}

The conceptual framework of this study is based on the Information-Motivation-Behavioral Skills (IMB) Model [19]. According to the model, the availability of information is the first of the fundamental components that affect healthy eating behavior. The second component of the model is motivation. The pregnant woman's motivation is her attitudes and evaluations about healthy eating behavior. Social motivation refers to pregnant women's perceived social support from other people for healthy eating. The last component in the model is behavioral skills, which represent the perceived skills of the pregnant woman regarding healthy eating behaviors (preparing, cooking, and storing food, calculating calories, reading food labels, etc.) and selfconfidence. The IMB model contributes to the development of healthy behaviors. In this way, the objective and subjective health outcomes of the individual are positively affected as a result of behavioral change [20]. It has been reported in the literature that programs based on the IMB Model increase individuals' self-efficacy, reduce negative attitudes, and are effective in developing positive behaviors [19, 21].

Although the IMB model was used to develop healthy eating behaviors in previous studies [22-24], to the best of our knowledge, no studies have yet been conducted with pregnant women on this topic. This study aims to test the effect of the IMB model components on the ON behavior of pregnant women and the health outcomes using a hypothetical model and to examine the relationship between these components. This study is significant in terms of guiding the interventions to develop healthy eating behaviors of pregnant women.

\section{Methodology}


This cross-sectional study was conducted with pregnant women who received a Non-Stress Test (NST called cardiotocography, records fetus's movement, heartbeat, and uterus contractions) at XXX University, Health Application and Research Center, Obstetrics Outpatient Clinic between January 2 and March 15, 2020.

Although there may a difference in daily routines in the hospital, it has been reported that an average of 10 NSTs was performed daily on pregnant women (200 monthly). For this limited population ( $N=2400$ annually), the sample size (n) was calculated to be 159 at a 95\% confidence level [25]. Also, taking into account the possible data loss, the questionnaire was administered to 359 pregnant women who were selected through the convenience sampling method and who met the inclusion criteria of the study.

The inclusion criteria were being a pregnant woman who is over the age of 18 , who can read and write, who is at gestational week 30 or over, who does not have a risky pregnancy, and who volunteered to participate in the study. Nine pregnant women who did not meet the inclusion criteria and who left some questions in the data collection forms unanswered were excluded from the study. As a result, the data obtained from 350 pregnant women were analyzed.

\section{Data Collection}

The data were collected using the face-to-face interview method. The data collection process lasted for about 15-20 minutes. The data collection form includes 14 questions aiming at collecting data about the demographic and obstetric characteristics of pregnant women and the following IMB components:

\section{Information}

The nutritional knowledge level of pregnant women was evaluated with eight statements (e.g. fats in processed meat products such as salami and sausages are harmful to health, the nutritional value of frozen products is lower than fresh foods) prepared by the researchers. Each correct answer received 1 point, while each incorrect answer was scored as 0 . In this study, the Kuder-Richardson (KR)-20 coefficient of the eight items was found to be 0.59 .

\section{Individual Motivation}

The Photographic Figure Rating Scale developed by Swami et al. (2008) was used to evaluate the individual motivation of pregnant women for nutrition [26]. The pregnant women were asked to rate their visual body perception by looking at the 10 female bodies given on the scale ( 1 underweight-10 overweight). Pregnant women's motivation for nutrition was evaluated by calculating the difference between their current visual body perception $\left(\mathrm{VBP}_{1}\right)$ and the perception of the ideal body they want to have in the future $\left(\mathrm{VBP}_{2}\right)$. As the score representing the difference gets further from zero (as the BMI gets higher), it is thought that pregnant women will exhibit more ON behaviors [27].

\section{Social Motivation (Social Support)}

The social motivation of pregnant women regarding nutrition was evaluated with the proposition "There are people who support me about having a healthy diet". The answer "yes" was scored as 1, while the answer "no" was scored as 0 . 


\section{Behavioral Skills}

The self-efficacy of pregnant women regarding healthy eating was evaluated with the Self-efficacy to Regulate Eating Habits Scale developed by Bandura (2006) [28] and adapted into Turkish by Sevinç and Argon (2014) [29]. The scale evaluates the performance of the participants in their regular nutrition routine. Each situation in the scale is scored in 10-unit intervals, between 0 (not possible) and 100 (absolutely possible). As the score increases, it is understood that the healthy eating self-efficacy of the individual is high. In the Turkish adaptation study of the scale, the Cronbach's Alpha coefficient was 0.98 [29]. It was found to be 0.90 in this study.

\section{Orthorexia Nervosa Self-Management Behaviors}

The ON behaviors of pregnant women were evaluated using the ORTO-11, which was developed by Donini et al. (2005) [30] and adapted to Turkish by Arusoğlu et al. (2008) [27]. ORTO investigates individuals' obsession with healthy food. The scale is a four-point Likert-type scale consisting of 11 items. Each item is scored between 1 (always) and 4 (never). Low scores indicate an increased ON tendency. In the original study [30], no Cronbach's alpha was reported. The Cronbach's alpha coefficient of the scale was 0.62 in the Turkish adaptation study and 0.54 in this study.

\section{Objective Health Outcome}

According to some studies [27, 31], since a high body mass index (BMI) can predict the ON tendency, the objective health outcomes were evaluated using the BMI in the current study. Since a high body mass index (BMI) can predict $\mathrm{ON}$ tendencies, the objective health outcomes were evaluated using the BMI, which is calculated by dividing body weight by the square of height in meters $\left(\mathrm{kg} / \mathrm{m}^{2}\right)$. The BMl grouping of pregnant women was made according to the classification of the American Medical Institute [32]. Based on this classification, if the pregnant woman's BMI is $<18.5$, she is considered underweight; if the $\mathrm{BMI}$ is $18.5 \leq \mathrm{BMI} \leq 24.9$, the weight is considered to be ideal; if the $\mathrm{BMI}$ is $25.0 \leq \mathrm{BMI} \leq 29.9$, the pregnant woman is considered to be overweight; and having a BMI higher than 30 (BMI $\geq 30.0)$ indicates obesity.

\section{Subjective Health Outcome}

Since $\mathrm{ON}$ is associated with impaired body image [33], the subjective health outcomes of pregnant women were evaluated with the "Perception of Body During Pregnancy" sub-dimension of the "Self-Perception of Pregnant Scale (SPPS)" developed by Kumcağız et al. (2017) [34]. This sub-dimension evaluates the negative perception of changes in the body during pregnancy on a four-point Likert-type scale and consists of five negative items. Each item is scored between 4 (always) and 1 (never). A high score indicates that body perception during pregnancy is negative. The Cronbach's alpha coefficient of the sub-dimension was 0.75 in the original study, 0.88 in this study.

\section{Hypothetical Model and Study Hypotheses}

The IMB model-based hypothetical model and research hypotheses are shown in Figure 1. Each one-way arrow (paths) in the hypothetical model represents the research hypotheses. 


\section{Data Analysis}

The mean \pm standard deviation of numerical variables and the number and percentage values of categorical variables were given. The compatibility of the data to normal distribution was tested with the Shapiro-Wilk test. Also, as the absolute values of the skewness and kurtosis numbers of the variables were below 2 , there was no obstacle in creating a model and the data were normally distributed [35]. Relationships between numerical variables were tested with the Pearson correlation coefficient to determine the presence of multicollinearity of variables. Cronbach's alpha coefficients were calculated to test the reliability of the scales. The goodness of fit of the hypothetical model was checked with the standardized regression coefficients and error variances in Confirmatory Factor Analysis (CFA). The maximum probability technique was used in SEM, and direct and indirect path coefficients were estimated using the Boostrap estimation method. To determine the fit of the hypothetical model, the ratio of chi-square to degrees of freedom ( $\left.{ }^{2} / \mathrm{df}\right)$, Goodness of Fit Index (GFI), Normed Fit Index (NFI), Incremental Fit Index (IFI), Comparative Fit Index (CFI), and Root Mean Square Error of Approximation (RMSEA) were used. If $x^{2} / d f$ is below 5 , it indicates an acceptable fit; and if it is below 2 , it indicates a perfect fit. A GFI, NFI, and IFI value of 0.90 and above and CFI values of 0.95 and above indicate a good fit. An RMSEA value below 0.08 reflects an acceptable fit [35-37]. The SPSS 22 and AMOS 21 software were used for statistical analysis, and the significance level was accepted as $p<.05$.

\section{Ethical Considerations}

Before the study, written permission was obtained from the Afyonkarahisar Clinical Research Ethics Committee (dated 07.02.2020 and numbered 2020/75) and from the institution where the study was conducted (dated 26/11/2019 and numbered E.20723). Informed consent of the participants was received. The procedures used in this study adhere to the tenets of the Declaration of Helsinki.

\section{Results}

\section{Sociodemographic and nutritional characteristics}

The average age of the pregnant women was $28.22 \pm 5.60$, the average duration of marriage was $6.82 \pm 5.27$ years, the average number of pregnancies was $2.74 \pm 1.78$, the average number of surviving children was 1.79 \pm 0.85 , and the average gestational week was $35.14 \pm 2.51$. Half of the pregnant women finished high school or university (50.8\%); 76\% were housewives; $93.6 \%$ had average/above-average income; $84 \%$ had social security. $24.9 \%$ of the pregnant women did not change their diet after getting pregnant, and $44.9 \%$ did not receive any training on nutrition during pregnancy. The pre-pregnancy BMI mean of the pregnant women was $25.49 \pm 5.20$, while the BMI means during the study was $29.66 \pm 5.15$. The average visual body perception score of pregnant women was $7.60 \pm 1.70$, and the average perception of the ideal body they want to have in the future was $4.32 \pm 1.37$. It was found that $26.6 \%$ of the pregnant women in the study had an ON tendency (Table 1).

\section{Correlations between variables and descriptive statistics}

Absolute values of skewness and kurtosis numbers for each measured variable were found between 0.03-1.20 and 0.02-1.01, respectively. These results show that the data is suitable for modeling and is normally 
distributed [35]. The correlation coefficients of the variables with significant correlations were found between 0.12 and 0.50 . When these values are below 0.70 , it means that there is no multicollinearity problem among the variables (Table 2).

\section{The fit statistics of the hypothetical model}

The goodness of fit of the hypothetical model was tested in two stages. In the first stage, the goodness of fit was tested by creating covariance matrices in CFA. The CFA results are $\mathrm{x}^{2} / \mathrm{df}=2.807, \mathrm{GFI}=0.98, \mathrm{NFI}=0.95$, $\mathrm{IFI}=0.96, \mathrm{CFI}=0.96$, and RMSEA $=0.072$ (Table 3 ). The regression weight between latent variables and measured variables was significant $(p<.01)$. There is no negative error variance. These results show that the latent variable and the measured variable define the model sufficiently [36].

In the second stage, which involves the SEM analysis, the effect of each latent variable on ON behavior and health outcomes was tested. Three of the eight paths suggested by the hypothetical model were found to be statistically significant $(p<.05)$. The goodness of fit indices obtained after the insignificant paths were removed from the model is as follows: $x^{2} / \mathrm{df}=1.592, \mathrm{GFI}=0.98, \mathrm{NFI}=0.95, \mathrm{IFI}=0.98, \mathrm{CFI}=0.986$ and RMSEA $=0.041$ (Table 3). It was observed that all values of the goodness of fit were at the recommended levels. Thus, it can be said that the hypothetical model reflects the IMB model well.

\section{Direct, indirect, and total effects of variables on health outcomes}

The paths (hypotheses) suggested in the hypothetical model were evaluated in terms of standardized regression coefficients and statistical significance. Higher levels of information lead to more ON selfmanagement behaviors $\left(\mathrm{H}_{3} ; \beta=-0.25, p<.001\right)$, explaining $6 \%$ of ON self-management behaviors variability. The higher motivation $\left(H_{7} ; \beta=0.71, p<.001\right)$ and tendency to more $\mathrm{ON}\left(\mathrm{H}_{8} ; \beta=-0.18, p=.001\right)$ were associated with better health outcomes, and they together account for $54 \%$ of the variability of health outcomes (Table 4 ; Figure 2).

When the indirect effects of variables on health outcomes were examined (Table 4; Figure 2), it was found that information indirectly affected the health outcomes $(\beta=0.04, p=.007)$. Higher levels of information are associated with higher $\mathrm{BMI}(\beta=0.03, p=.007)$ and a negative body perception $(\beta=-0.03, p=.007)$. It was revealed that motivation indirectly affected $\mathrm{BMI}(\beta=0.46, p=.006)$ and body perception $(\beta=-0.49, p=.011)$. The tendency to ON self-management behaviors indirectly affects $\mathrm{BMI}(\beta=-0.11, p=.009)$ and body perception $(\beta=0.12, p=.02)$.

\section{Discussion}

Due to physical changes, concerns about body image and weight gain increase during pregnancy [38]. Although some pregnant women reduce their calorie intake and do excessive exercise (pregorexia) [39], preoccupation with healthy eating gradually increases and poses a threat to ON [17]. Nevertheless, ON behavior is generally neglected during pregnancy. This study aimed to reveal how the IMB components affect ON behaviors and health outcomes of pregnant women. The results of the study show that the information and motivation about healthy nutrition affect the $\mathrm{ON}$ tendency and health outcomes in pregnant women. 
The IMB model assumes that a knowledgeable and motivated person is more prone to developing relevant behavioral skills and is more likely to engage in this behavior [40]. In parallel to the model, our study revealed that as the knowledge of pregnant women about healthy eating increased, their tendency to orthorexic behavior also increased. Also, it has been found that high levels of knowledge and motivation about healthy eating affect health outcomes. Similarly, interventions based on the IMB model have been found to improve the correct food selection of university students [41], diet and exercise self-care behaviors of adults with diabetes [42], and healthy lifestyle and mental well-being of pregnant women with high BMI [43].

Motivation is necessary to gain optimal nutritional behavior [44]. Many pregnant women have a high individual motivation to improve health behaviors. Pregnancy is also considered the best time to combat problems such as bad eating habits and inadequate physical activity [39]. The majority of pregnant women in our study stated that they changed their nutritional attitude during pregnancy to be healthier. Similarly, a study conducted in Iran revealed that the behavioral intentions of pregnant women positively affected their healthy eating behaviors [45]. These results not only show that the individual motivation of pregnant women about healthy eating increases during pregnancy, but also indicates that the risk of ON increases.

The effect of social support on healthy nutrition during pregnancy is controversial in the literature. In some studies, social support has been recognized as a powerful precursor to developing a healthy lifestyle during pregnancy [46], and the social effects of healthy eating behaviors have been attributed to families and spouses [47]. In our study, the motivation for healthy nutrition was found to be higher in pregnant women who perceive their external appearance as close to ideal and who have high social support for healthy nutrition. Also, pregnant women with high motivation have higher BMI and more positive body perception. However, overweight and obese pregnant women in Ireland think that the environment they live in does not support healthy eating behaviors [48]. According to a study conducted in Australia, the BMls of pregnant women do not affect their perceptions of social support associated with healthy eating. Both women with normal BMI and overweight women appear to be motivated in terms of healthy eating and avoiding excessive weight gain during pregnancy [49]. Interestingly, some women are motivated by aesthetic and social expectations rather than health concerns [50].

According to some studies, since impaired body image [33,51] and high BMI [27] are associated with ON tendency, these variables were evaluated as objective and subjective health outcomes in our study. Our study revealed that as the information, motivation, and $\mathrm{ON}$ tendencies of pregnant women increased, they had higher BMI values and more positive body perception. In other words, satisfaction with visual body perception and higher BMI appear to be associated with ON in pregnancy. Similarly, in a study conducted in Norway, increased BMI during pregnancy was found to be associated with maternal eating disorders [52]. Arusoğlu et al.' study revealed that with distorted eating attitudes and obsessive-compulsive symptoms, high BMI is a powerful predictor of ON [27]. Barnes and Caltabiano (2017) found that stronger ON tendency was associated with higher levels of perfectionism, more appearance orientation, and anxiety about being overweight [53]. However, some studies showing that BMI was not associated with ORTO-15 scores among Turkish university students [54], and young Italian adults [55].

Those who are in the extreme $25 \%$ according to the distribution of the total ORTO score in healthy food selection assessment (27 points and less for ORTO-11) were defined as "health fanatics" by Donini et al. [30]. 
This limit has been at the same time considered as the criteria for the diagnosis of ON. One out of every four pregnant women who participated in our study could be a health fanatic with a tendency to ON. The frequency of ON we revealed (26.6\%) seems to be slightly higher than the frequency found by the limited number of studies about ON in pregnant women (21.4\%) [9]. It is known that ON emerges in all cultures familiar with the "ideal woman" figure and its prevalence has been increasing rapidly [27]. Being extremely concerned about being "thin", which the media promotes as "healthy, fashionable and perfect", seems to continue to contribute to the prevalence of $\mathrm{ON}$, especially in a period such as pregnancy, when weight gain is inevitable and body image is affected [56].

\section{Limitations Of The Study}

This study has some limitations. First, this study is limited to its sample. Therefore, the results are limited in terms of generalizability. Second, the data is based on the statements of the participants, and it has not been clinically confirmed. Third, the extent of ORTO-11 in determining ON may be limited due to its psychometric properties. Therefore, it cannot be excluded that the ORTO-11 measures "healthy eating" rather than "orthorexic eating behavior." Hence, the results reveal healthier eating in general, which does not necessarily have to be orthorexic/pathological and which could then be health-promoting instead of health-damaging.

\section{What Is Already Known On This Subject?}

Due to physical changes, concerns about body image and weight gain increase during pregnancy. Although some pregnant women reduce their calorie intake and do excessive exercise, preoccupation with healthy eating gradually increases and poses a threat to $\mathrm{ON}$. However, $\mathrm{ON}$ is an issue that is neglected during pregnancy. Studies about ON during pregnancy are extremely limited.

\section{What Does This Study Add?}

The study shows that high levels of information and motivation of pregnant women about healthy eating affect $\mathrm{ON}$ tendency and health outcomes. The findings are significant in that they lead and guide the interventions for the detection, prevention, and treatment of ON during pregnancy.

\section{Conclusion}

The results of the study revealed that high levels of knowledge and motivation about healthy eating affect ON tendency and health outcomes. This study is one of the first studies that examine ON behaviors and the factors influencing ON behaviors during pregnancy based on the IMB model. The results of the study are valuable in that they can lead and guide the studies about ON during pregnancy. It is recommended to routinely question the history of excessive focus on body image and eating disorders in all pregnant women, especially in those with positive body image and high BMI. It is thought that interventions based on the IMB model may contribute to the reduction of morbidity and mortality that can be caused by $\mathrm{ON}$ behaviors during pregnancy and to the improvement of maternal and fetal outcomes.

\section{Declarations}


Funding No funding was received.

Conflict of interest The authors declare that they have no conflict of interest in the research and writing of this manuscript.

\section{Ethical statement}

All procedures performed in studies involving human participants were by the ethical standards of the institutional and/or national research committee and with the 1964 Helsinki Declaration and its later amendment or comparable ethical standards.

\section{Informed consent}

Informed consent was administered to all participants.

\section{References}

1. Bratman S (1997) Health Food Junkie. Yoga J 8:42-50

2. Oğur S, Aksoy A, Güngör Ş (2015) Determination of the orthorexia nervosa tendency in university students. BEU J Sci 4:92-102. https://doi.org/10.17798/beufen.95626

3. Koven NS, Abry AW (2015) The clinical basis of orthorexia nervosa: emerging perspectives. Neuropsychiatr Dis Treat 11:385-394. https://doi.org/10.2147/NDT.S61665

4. American Psychiatric Association (2020) Diagnostic and Statistical Manual of Mental Disorders (DSM-5). https://www.psychiatry.org/psychiatrists/practice/dsm. Accessed 17 Jan 2021

5. Dunn TM, Bratman S (2016) On orthorexia nervosa: A review of the literature and proposed diagnostic criteria. Eat Behav 21:11-17. https://doi.org/10.1016/j.eatbeh.2015.12.006

6. Pieczykolan A, Flis E, Bień A (2017) Eating disorders during pregnancy. Piel Zdr Publ 7:223-226. https://doi.org/10.17219/pzp/66326

7. Dunn TM, Gibbs J, Whitney N, Starosta A (2017) Prevalence of orthorexia nervosa is less than $1 \%$ : data from a US sample. Eat Weight Disord 22:185-192. https://doi.org/10.1007/s40519-016-0258-8

8. Oberle CD, De Nadai AS, Aspen ; Madrid L (2021) Orthorexia Nervosa Inventory (ONI): development and validation of a new measure of orthorexic symptomatology. Eat Weight Disord - Stud Anorexia Bulim Obes 26:609-622. https://doi.org/10.1007/s40519-020-00896-6

9. İpkirmaz IB, Saka M (2020) The evaluation of healthy nutrition obsession (Orthorexia Nervosa) and eating attitudes of pregnant women. Başkent Univ Fac Heal Sci J 5:17-30

10. Varga M, Dukay-Szabó S, Túry F, Van Furth Eric F (2013) Evidence and gaps in the literature on orthorexia nervosa. Eat Weight Disord 18:103-111. https://doi.org/10.1007/s40519-013-0026-y

11. Currin L, Schmidt U, Treasure J, Jick H (2005) Time trends in eating disorder incidence. Br J Psychiatry 186:132-135. https://doi.org/10.1192/bjp.186.2.132

12. Dukay-Szabó S, Varga M, Túry F (2016) Eating disorders and pregnancy -A review of literature. Ideggyogy Sz 69:299-305. https://doi.org/10.18071/isz.69.0299 
13. Watson HJ, Von Holle A, Knoph C et al (2015) Psychosocial factors associated with bulimia nervosa during pregnancy: An internal validation study. Int J Eat Disord 48:654-662. https://doi.org/10.1002/eat.22361

14. Abramowitz JS, Nelson CA, Rygwall R, Khandker M (2007) The cognitive mediation of obsessivecompulsive symptoms: A longitudinal study. J Anxiety Disord 21:91-104. https://doi.org/10.1016/j.janxdis.2006.05.003

15. Siriken B, Siriken F, Ünsal C, Çiftcì G (2018) Nutrition and Epigenetic. J Harran Univ Fac Vet Med 12-18

16. Brytek-Matera A, Gramaglia C, Gambaro E et al (2018) The psychopathology of body image in orthorexia nervosa. J Psychopathol 24:133-140

17. Kadioğlu M, Oskay Ü (2017) The effects of eating disorders on pregnancy and postpartum period. KASHED 3:40-53

18. Santos AM dos, Benute GRG, Santos NO dos, et al (2017) Presence of eating disorders and its relationship to anxiety and depression in pregnant women. Midwifery 51:12-15.

https://doi.org/10.1016/j.midw.2017.05.005

19. Fisher JD, Fisher WA (1992) Changing AIDS - Risk Behavior. Psychol Bull 111:455-474. https://doi.org/10.1037/0033-2909.111.3.455

20. Osborn CY, Amico KR, Fisher WA et al (2010) An Information-Motivation-Behavioral skills analysis of diet and exercise behavior in Puerto Ricans with diabetes. J Health Psychol 15:1201-1213. https://doi.org/10.1177/1359105310364173

21. Fisher JD, Fisher WA, Misovich SJ et al (1996) Changing AIDS risk behavior: effects of an intervention emphasizing AIDS risk reduction information, motivation, and behavioral skills in a college student population. Health Psychol 15:114-123. https://doi.org/10.1037//0278-6133.15.2.114

22. Daly P, Pace T, Berg J et al (2016) A mindful eating intervention: A theory-guided randomized anti-obesity feasibility study with adolescent Latino females. Complement Ther Med 28:22-28. https://doi.org/10.1016/j.ctim.2016.07.006

23. Sinley RC, Albrecht JA, Author C, State M (2018) Application of the IMB Model to the reported intake of fruits and vegetables of Native American Children. J Health Dispar Res Pract 11:16-30

24. Peyman N, Abdollahi M (2017) Using of information-motivation-behavioral skills model on nutritional behaviors in controlling anemia among girl students. J Res Heal Soc Dev Heal Promot Res Cent 7:736744. https://doi.org/10.18869/acadpub.jrh.7.2.736

25. Özdamar K (2015) Biostatistics with SPSS, 10th edn. Nisan Kitapevi, Eskişehir

26. Swami V, Salem N, Furnham A, Tovée MJ (2008) Initial examination of the validity and reliability of the female photographic figure rating scale for body image assessment. Pers Individ Dif 44:1752-1761. https://doi.org/10.1016/j.paid.2008.02.002

27. Arusoğlu G, Kabakçi E, Köksal G, Kutluay Merdol T (2008) Orthorexia nervosa and adaptation of ORTO-11 into Turkish. Turkish J Psychiatry 19:283-291

28. Bandura A (2006) Guide for Constructing Self-Efficacy Scales. In: Urdan T, Pajares F (eds) Self-Efficacy Beliefs of Adolescents. Information Age Pub, Greenwich, pp 307-337 
29. Sevinç S, Argon G (2014) Turkish reliability and validity of self-effıcacy to regulate eating habits scale in the cardiac patients. J Ege Univ Nurs Fac 30:19-33

30. Donini LM, Marsili D, Graziani MP et al (2005) Orthorexia nervosa: Validation of a diagnosis questionnaire. Eat Weight Disord 10:e28-e32. https://doi.org/10.1007/BF03327537

31. Oberle CD, Samaghabadi RO, Hughes EM (2017) Orthorexia nervosa: Assessment and correlates with gender, BMI, and personality. Appetite 108:303-310. https://doi.org/10.1016/j.appet.2016.10.021

32. Institute of Medicine (2009) Weight gain during pregnancy: reexamining the guidelines. National Academies Press, Washington (DC)

33. Varga M, Thege BK, Dukay-Szabó S et al (2014) When eating healthy is not healthy: Orthorexia nervosa and its measurement with the ORTO-15 in Hungary. BMC Psychiatry 14:1-11. https://doi.org/10.1186/1471-244X-14-59

34. Kumcağiz H, Ersanli E, Murat N (2017) The development of a self-perception of pregnants scale and its psychometric features. J Psychiatr Nurs 8:23-31. https://doi.org/10.14744/phd.2017.12599

35. Kline R (2011) Principles and Practice of Structural Equation Modeling, 3rd edn. The Guilford Press, New York

36. Bayram N (2013) Introduction to Structural Equation Modeling AMOS Applications, 2. edn. Ezgi Kitapevi, Istanbul

37. Doğan İ, Özdamar K (2017) The effect of different data structures, sample sizes on model fit measures. Commun Stat Simul Comput 46:7525-7533. https://doi.org/10.1080/03610918.2016.1241409

38. Easter A, Treasure J, Micali N (2011) Fertility and prenatal attitudes towards pregnancy in women with eating disorders: Results from the Avon Longitudinal Study of Parents and Children. BJOG An Int J Obstet Gynaecol 118:1491-1498. https://doi.org/10.1111/j.1471-0528.2011.03077.x

39. Kominiarek MA, Peaceman AM (2017) Gestational weight gain. Am J Obstet Gynecol 217:642-651. https://doi.org/10.1016/j.ajog.2017.05.040

40. Fisher WA, Fisher JD, Harman J (2003) The Information-Motivation-Behavioral Skills Model: A General Social Psychological Approach to Understanding and Promoting Health Behavior. In: Social Psychological Foundations of Health and Illness. Blackwell Publishing Ltd, pp 82-106

41. Maupome AL, Muro Ma de los ÁV, Garduño Ma Luisa M (2020) Improving food choices when eating with peers: An IMB Model-based weight-loss intervention. Curr Dev Nutr 4:1327-1327.

https://doi.org/10.1093/cdn/nzaa059_044

42. Gavgani RM, Poursharifi H, Aliasgarzadeh A (2010) Effectiveness of Information-Motivation and Behavioral skill (IMB) model in improving self-care behaviors \& Hba1c measure in adults with type2 diabetes in Iran-Tabriz. Procedia - Soc Behav Sci 5:1868-1873.

https://doi.org/10.1016/j.sbspro.2010.07.380

43. Tabari NSM, Faramarzi M, Shirvani MA et al (2019) Effect of counseling based on Information-Behavioral Motivation Model on health promoting lifestyle behaviors and psychological well-being in obese and overweight pregnant women: a randomized clinical trial. J Maz Univ Med Sci 29:99-110

44. Khoramabadi M, Dolatian M, Hajian S et al (2015) Effects of Education Based on Health Belief Model on Dietary Behaviors of Iranian Pregnant Women. Glob J Health Sci 8:230-239. 
https://doi.org/10.5539/gjhs.v8n2p230

45. Chitsaz A, Javadi M, Lin C-Y, Pakpour AH (2017) The predictors of healthy eating behavior among pregnant women: An application of the Theory of Planned Behavior. Int J Pediatr 5:5897-5905. https://doi.org/10.22038/ijp.2017.25576.2176

46. Jelsma JGM, Van Leeuwen KM, Oostdam N et al (2016) Beliefs, barriers, and preferences of European overweight women to adopt a healthier lifestyle in pregnancy to minimize risk of developing gestational diabetes mellitus: An explorative study. J Pregnancy 2016:1-11. https://doi.org/10.1155/2016/3435791

47. Sharafi SF, Javadi M, Barikani A (2016) Reliability and validity of Short Food Frequency Questionnaire among pregnant females. Biotechnol Heal Sci 3:e34608. https://doi.org/10.17795/bhs-34608

48. O’Brien OA, Lindsay KL, McCarthy M et al (2017) Influences on the food choices and physical activity behaviours of overweight and obese pregnant women: A qualitative study. Midwifery 47:28-35. https://doi.org/10.1016/j.midw.2017.02.003

49. de Jersey SJ, Mallan K, Callaway L et al (2017) A cross-sectional comparison of predisposing, reinforcing, and enabling factors for lifestyle health behaviors and weight gain in healthy and overweight pregnant women. Matern Child Health J 21:626-635. https://doi.org/10.1007/s10995-016-2148-0

50. Scott J, Oxlad M, Dodd J et al (2020) Creating healthy change in the preconception period for women with overweight or obesity: A qualitative study using the Information - Motivation - Behavioural Skills Model. J Clin Med 9:1-20. https://doi.org/10.3390/jcm9103351

51. Gezer C, Kabaran S (2013) The risk of orthorexia nervosa for female students studying nutrition and dietetics. SDÜ J Heal Sci 4:14-22

52. Watson HJ, Zerwas S, Torgersen L et al (2017) Maternal eating disorders and perinatal outcomes: A threegeneration study in the Norwegian mother and child cohort study. J Abnorm Psychol 126:552-564. https://doi.org/10.1037/abn0000241

53. Barnes MA, Caltabiano ML (2017) The interrelationship between orthorexia nervosa, perfectionism, body image and attachment style. Eat Weight Disord 22:177-184. https://doi.org/10.1007/s40519-016-0280-x

54. Sanlier N, Yassibas E, Bilici S et al (2016) Does the rise in eating disorders lead to increasing risk of orthorexia nervosa? Correlations with gender, education, and body mass index. Ecol Food Nutr 55:266278. https://doi.org/10.1080/03670244.2016.1150276

55. Cinosi E, Matarazzo I, Marini S et al (2015) Prevalence of Orthorexia Nervosa in a Population of Young Italian Adults. Eur Psychiatry 30:1330. https://doi.org/10.1016/s0924-9338(15)31038-5

56. Mandera A, Pawlikowska A, Szuster EM et al (2019) The pregorexia - anorexia during the pregnancy. J Educ Heal Sport 9:137-144. https://doi.org/10.5281/zenodo.2718477

\section{Tables}

Table 1 Sociodemographic and nutritional characteristics of pregnant women $(N=350)$ 


\begin{tabular}{|c|c|}
\hline & $M \pm \mathrm{SD}(\min -\max )$ OR $n(\%)$ \\
\hline $\begin{array}{l}\text { Age } \\
\text { Duration of marriage }\end{array}$ & $\begin{array}{l}28.22 \pm 5.60(18-45) \\
6.82 \pm 5.27(1-25)\end{array}$ \\
\hline $\begin{array}{l}\text { Number of pregnancies } \\
\text { Number of living children } \\
\text { Gestational week } \\
\text { Pre-pregnancy BMI } \\
\text { Current BMI }\end{array}$ & $\begin{array}{c}2.74 \pm 1.78(1-13) \\
1.79 \pm 0.85(1-4) \\
35.14 \pm 2.51(30-40) \\
25.49 \pm 5.20(15.43-42.66) \\
29.66 \pm 5.15(19.10-48.27)\end{array}$ \\
\hline Present visual body perception $\left(\mathrm{VBP}_{1}\right)$ & $7.60 \pm 1.70(2-10)$ \\
\hline $\begin{array}{l}\text { The ideal visual body perception in the future }\left(\mathrm{VBP}_{2}\right) \\
\text { Orthorexia Nervosa tendency (total score } \leq 27)\end{array}$ & $\begin{array}{l}4.32 \pm 1.37(1-8) \\
93(26.6)\end{array}$ \\
\hline \multirow[t]{4}{*}{ Education } & $55(15.7)$ \\
\hline & $117(33.4)$ \\
\hline & $103(29.4)$ \\
\hline & $75(21.4)$ \\
\hline \multirow[t]{4}{*}{ Occupation } & $266(76.0)$ \\
\hline & $39(11.1)$ \\
\hline & $15(4.3)$ \\
\hline & $30(8.6)$ \\
\hline \multirow[t]{3}{*}{ Income level } & $122(34.9)$ \\
\hline & $209(59.7)$ \\
\hline & $19(5.4)$ \\
\hline \multirow[t]{2}{*}{ Social security } & $294(84.0)$ \\
\hline & $56(16.0)$ \\
\hline \multirow[t]{2}{*}{ Smoking } & $28(8.0)$ \\
\hline & $322(92.0)$ \\
\hline \multirow[t]{3}{*}{ Has there been a change in the diet during pregnancy? } & $139(39.7)$ \\
\hline & $87(24.9)$ \\
\hline & $124(35.4)$ \\
\hline \multirow[t]{5}{*}{ From whom did you receive information on nutrition during pregnancy? } & $157(44.9)$ \\
\hline & $37(10.6)$ \\
\hline & $91(26.0)$ \\
\hline & 59 (16.9) \\
\hline & $6(1.7)$ \\
\hline Total & $350(100.0)$ \\
\hline
\end{tabular}

$B M I$ Body Mass Index, $V B P$ visual body perception, $O N$ Orthorexia Nervosa

Table 2 Descriptive statistics for scale scores $(N=350)$ 


\begin{tabular}{|c|c|c|c|c|c|c|c|c|c|c|}
\hline & \multirow{2}{*}{$\begin{array}{l}\text { Min- } \\
\text { Max }\end{array}$} & \multirow[b]{2}{*}{$M \pm \mathrm{SD}$} & \multirow[b]{2}{*}{ Skewness } & \multirow[b]{2}{*}{ Kurtosis } & \multicolumn{6}{|c|}{ Pearson Correlation } \\
\hline & & & & & 1 & 2 & 3 & 4 & 5 & 6 \\
\hline 1. & & & & & & & & & & \\
\hline Information & $0-8$ & $4.35 \pm 1.78$ & -0.03 & -0.40 & & & & & & \\
\hline $\begin{array}{l}\text { 2. Behavioral } \\
\text { skills }\end{array}$ & $\begin{array}{l}100- \\
1100\end{array}$ & $834.25 \pm 226.15$ & -1.12 & 0.90 & $0.18^{* *}$ & & & & & \\
\hline $\begin{array}{l}\text { 3. Individual } \\
\text { motivation }\end{array}$ & $(-9)-5$ & $(-3.28) \pm 1.96$ & 0.18 & 0.37 & -0.01 & 0.01 & & & & \\
\hline $\begin{array}{l}\text { 4. Social } \\
\text { motivation }\end{array}$ & $0-1$ & $0.75 \pm 0.42$ & -1.20 & -0.55 & $0.12 *$ & 0.03 & $-0.21 * *$ & & & \\
\hline $\begin{array}{l}\text { 5. ON Self- } \\
\text { management }\end{array}$ & $17-37$ & $29.40 \pm 3.80$ & -0.69 & -0.02 & $-0.25^{* *}$ & -0.04 & 0.08 & 0.00 & & \\
\hline $\begin{array}{l}\text { 6. Objective } \\
\text { health } \\
\text { outcome } \\
\text { (BMI) }\end{array}$ & $2-4$ & $3.25 \pm 0.72$ & -0.42 & -1.01 & -0.01 & 0.00 & $-0.48^{* *}$ & 0.10 & $-0.13^{* *}$ & \\
\hline $\begin{array}{l}\text { 7. Subjective } \\
\text { health } \\
\text { outcome } \\
\text { (SPPS) }\end{array}$ & $5-20$ & $14.92 \pm 4.31$ & -0.69 & -0.53 & 0.02 & $0.16^{* *}$ & $0.50 * *$ & -0.09 & $0.18^{* *}$ & $-0.44 * *$ \\
\hline
\end{tabular}

ON Orthorexia Nervosa, BMI Body Mass Index, SPPS Self-Perception of Pregnant Scale

$* \mathrm{p}<.05$

$* * \mathrm{p}<.01$

Table 3 Fit statistics and reference criteria of the final model

\begin{tabular}{lcccccc}
\hline & $\mathrm{x}^{2} / d f$ & GFI & NFI & IFI & CFI & RMSEA \\
\hline Criterion & $\leq 5$ & $\geq 0.90$ & $\geq 0.90$ & $\geq 0.90$ & $\geq 0.95$ & $\leq 0.08$ \\
Confirmatory Factor Analysis & 2.807 & 0.98 & 0.95 & 0.96 & 0.96 & 0.072 \\
Hypothetical Model & 2.645 & 0.98 & 0.93 & 0.95 & 0.95 & 0.069 \\
Final Model & 1.592 & 0.98 & 0.95 & 0.98 & 0.98 & 0.041 \\
\hline
\end{tabular}

$x^{2} / d f$ The Minimum Discrepancy Divided by its Degrees of Freedom, GFI Goodness of Fit Index, NFI Normed Fit Index, IFI Incremental Fit Index, CFI Comparative Fit Index, RMSEA Root Mean Square Error of Approximation

Table 4 Effects of exogenous variables on endogenous variable in the final model $(N=350)$ 


\begin{tabular}{|c|c|c|c|c|c|c|c|c|}
\hline Endogenous Variable & & Exogenous variable & $\beta$ & $\mathrm{CR}(p)$ & SMC & $\operatorname{SDE}(p)$ & SIE $(p)$ & STE $(p)$ \\
\hline ON self-management & $\neg$ & Information & -0.25 & $-4.92(* * *)$ & 0.06 & $\begin{array}{l}-0.25 \\
(.016)\end{array}$ & & $\begin{array}{l}-0.25 \\
(.016)\end{array}$ \\
\hline \multirow[t]{3}{*}{ Health outcome } & $\neg$ & Information & & & 0.54 & & $\begin{array}{l}0.04 \\
(.007)\end{array}$ & $\begin{array}{l}0.04 \\
(.007)\end{array}$ \\
\hline & $\neg$ & Motivation & 0.71 & $3.85(* * *)$ & & $\begin{array}{c}0.71 \\
(.011)\end{array}$ & & $\begin{array}{l}0.71 \\
(.011)\end{array}$ \\
\hline & $\neg$ & $\begin{array}{l}\text { ON self- } \\
\text { management }\end{array}$ & -0.18 & $\begin{array}{l}-3.22 \\
(.001)\end{array}$ & & $\begin{array}{l}-0.18 \\
(.013)\end{array}$ & & $\begin{array}{l}-0.18 \\
(.013)\end{array}$ \\
\hline \multirow[t]{3}{*}{ Objective health outcome (BMI) } & $\neg$ & Information & & & & & $\begin{array}{l}0.03 \\
(.007)\end{array}$ & $\begin{array}{l}0.03 \\
(.007)\end{array}$ \\
\hline & $\neg$ & Motivation & & & & & $\begin{array}{l}0.46 \\
(.006)\end{array}$ & $\begin{array}{l}0.46 \\
(.006)\end{array}$ \\
\hline & $\neg$ & $\begin{array}{l}\text { ON self- } \\
\text { management }\end{array}$ & & & & & $\begin{array}{l}-0.11 \\
(.009)\end{array}$ & $\begin{array}{l}-0.11 \\
(.009)\end{array}$ \\
\hline \multirow[t]{3}{*}{$\begin{array}{l}\text { Subjective health outcome } \\
\text { (SPPS) }\end{array}$} & $\neg$ & Information & & & & & $\begin{array}{l}-0.03 \\
(.007)\end{array}$ & $\begin{array}{l}-0.03 \\
(.007)\end{array}$ \\
\hline & $\neg$ & Motivation & & & & & $\begin{array}{l}-0.49 \\
(.011)\end{array}$ & $\begin{array}{l}-0.49 \\
(.011)\end{array}$ \\
\hline & $\neg$ & $\begin{array}{l}\text { ON self- } \\
\text { management }\end{array}$ & & & & & $\begin{array}{c}0.12 \\
(.020)\end{array}$ & $\begin{array}{c}0.12 \\
(.020)\end{array}$ \\
\hline
\end{tabular}

ON Ortorexia Nevrosa, BMI Body Mass Index, SPPS Self-Perception of Pregnant Scale, $\beta$ Standardized Regression Weight, $C R$ Critical Ratio, SMC Squared Multiple Correlations, SDE Standardized Direct Effects, SIE Standardized Indirect Effects, STE Standardized Total Effects

$* * * p<.001$

\section{Figures}

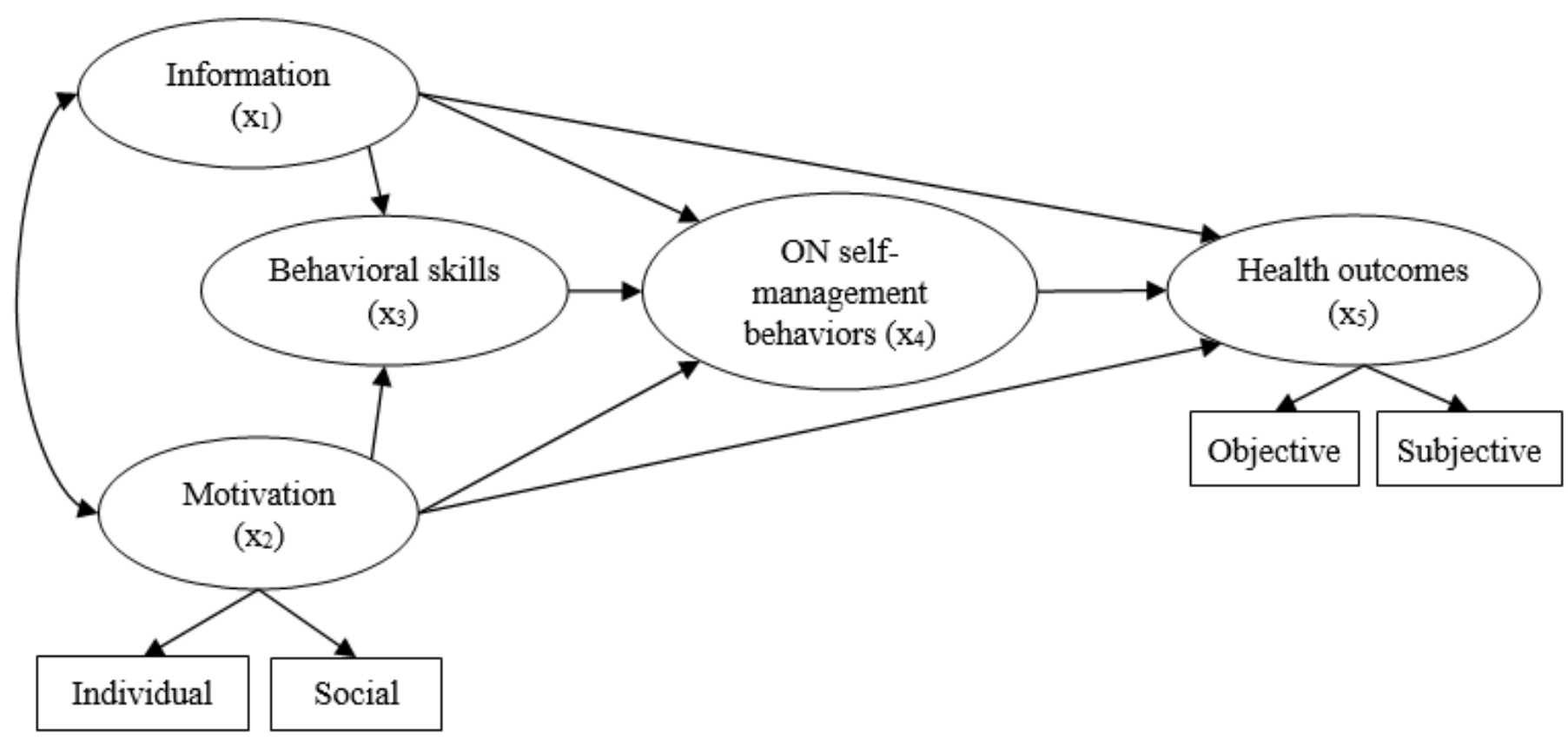

Figure 1

1 Hypothetical model and research hypotheses: $\mathrm{H} 1(\mathrm{x} 1 \rightarrow \mathrm{x} 3)$ Information affects behavioral skills $\mathrm{H} 2(\mathrm{x} 2 \rightarrow$ x3) Motivation affects behavioral skills $\mathrm{H} 3(\mathrm{x} 1 \rightarrow \mathrm{x} 4)$ Information affects Orthorexia Nervosa [ON] selfmanagement behaviors $\mathrm{H} 4(\mathrm{x} 2 \rightarrow \mathrm{x} 4)$ Motivation affects $\mathrm{ON}$ self-management behaviors $\mathrm{H} 5(\mathrm{x} 3 \rightarrow \mathrm{x} 4)$ 
Behavioral skills affect ON self-management behaviors $\mathrm{H} 6(\mathrm{x} 1 \rightarrow \mathrm{x} 5)$ Information affects health outcomes $\mathrm{H} 7$ $(\mathrm{x} 2 \rightarrow \mathrm{x} 5)$ Motivation affects health outcomes $\mathrm{H} 8(\mathrm{x} 4 \rightarrow \mathrm{x} 5)$ ON self-management behaviors affect health outcomes

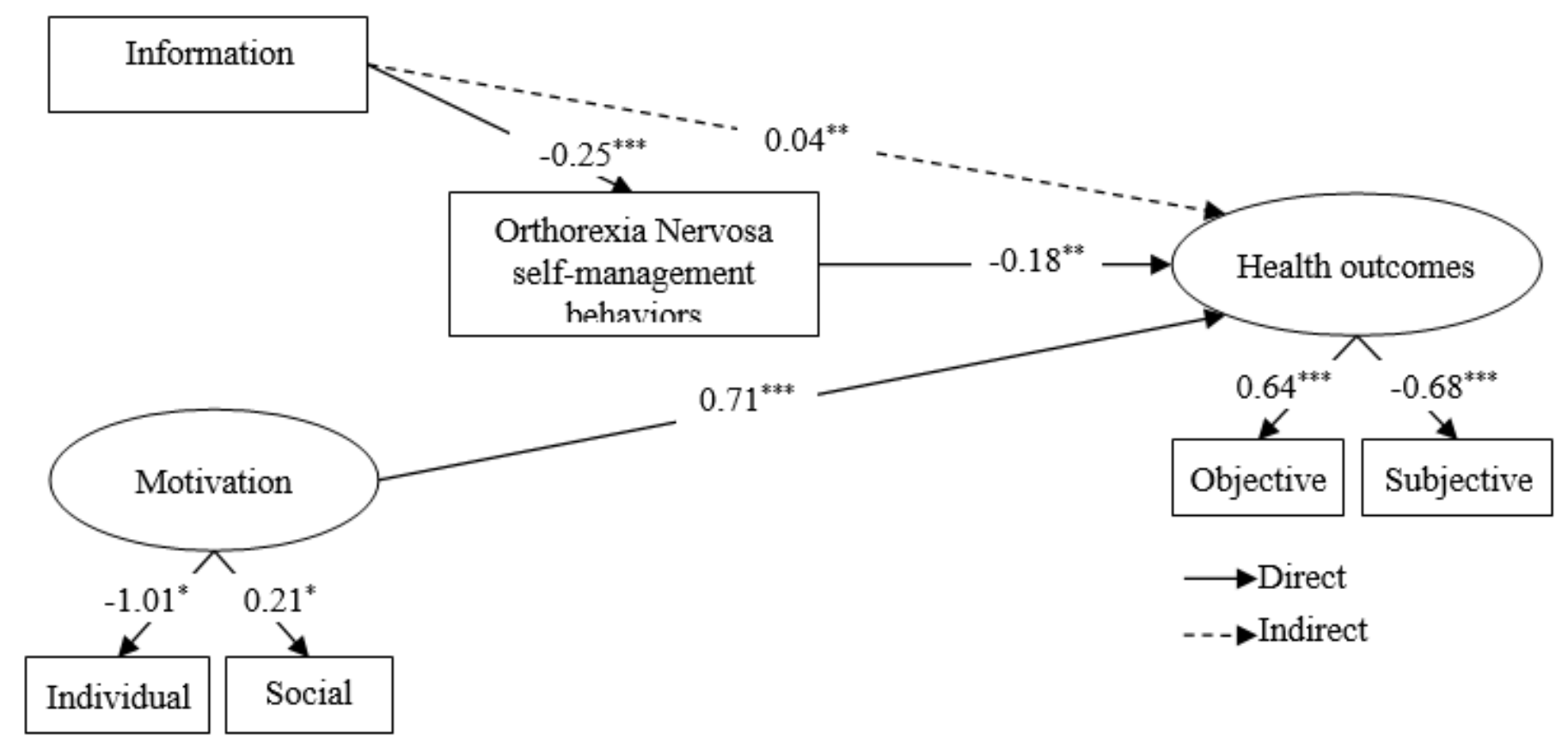

\section{Figure 2}

Path diagram of the final model ${ }^{*} p<.05^{* \star} p<.01{ }^{* \star *} \mathrm{p}<.001$ 